\title{
PATIENTS PROFILE AT THE SLEEP APNEA OUTPATIENT CLINIC AT A UNIVERSITY HOSPITAL
}

\section{PERFIL DOS PACIENTES NO AMBULATÓRIO DE APNEIA DO SONO EM UM HOSPITAL UNIVERSITÁRIO}

Natania Tuanny Damasceno Inácio1; Juliane Patrícia Grigório da Silva1; Lidiane Maria de Brito Macedo Ferreira ${ }^{3}$; Alexandre Augusto Fernandes ${ }^{4}$.

1. Physician, Otorhinolaryngology resident. Federal University of Rio Grande do Norte (UFRN). Natal, RN. Brazil.

2. Adjunct Professor at Otorhinolaryngology on Department of Surgery, Federal University of Rio Grande do Norte (UFRN). Natal, RN. Brazil.

3. Otorhinolaryngologist on Onofre Lopes University Hospital - EBSERH (Empresa Brasileira de Serviços Hospitalares) UFRN, Natal-RN. Brazil.

Department of Surgery, Federal University of Rio Grande do Norte (UFRN). Brazil.

Financial Support: None.

Conflict of interest: None.

Otorhinolaryngology and Head and Neck Service at Onofre Lopes University Hospital - Av. Nilo Peçanha, 619A - Petrópolis, Natal - RN CEP: 59012-300Natania Tuanny Damasceno Inácio. Email: natanytuck@hotmail.com

Submitted: may 04; accepted after revision: may 12, 2020.

\section{ABSTRACT}

Introduction: Obstructive sleep apnea syndrome (OSAS) is characterized by recurrent collapses of the pharyngeal region during sleep, resulting in a substantial reduction in airflow (apnea and hypopnea), despite respiratory efforts. Objective: To report the profile of patients referred to the Sleep Apnea Outpatient Clinic of Hospital Universitário Onofre Lopes (HUOL), emphasizing on the main risk factors associated with OSAS. Methods: It is retrospective study, cross-sectional, in which data obtained by reviewing medical records of patients seen at the sleep apnea outpatient clinic between 2017 and 2019 were used. Results: Medical records of 43 patients were evaluated, being $(62,8 \%)$ male and $(37.2 \%)$ female. All patients underwent previous screening before polysomnography, being divided into three groups: Group I - with mild OSAS: 8 patients (18.6\%); Group II - with moderate OSAS: 18 patients (41.8\%); Group III - with severe OSAS: 17 patients (39.5\%). Conclusion: Sleep apnea syndrome is commonly correlated with metabolic syndrome.

Keywords: Snoring, sleep apnea, polysomnography. 


\section{RESUMO}

Introdução: A síndrome da apneia obstrutiva do sono (SAOS) é caracterizada por colapsos recorrentes da região faríngea durante o sono, resultando em uma redução substancial no fluxo aéreo (apneia e hipopneia), apesar dos esforços respiratórios. Objetivo: Relatar o perfil dos pacientes encaminhados ao Ambulatório de Apneia do Sono do Hospital Universitário Onofre Lopes (HUOL), enfatizando os principais fatores de risco associados à SAOS. Métodos: Trata-se de um estudo retrospectivo, transversal, no qual foram utilizados dados obtidos através da revisão de prontuários de pacientes atendidos no ambulatório de apneia do sono entre 2017 e 2019. Resultados: Foram avaliados prontuários de 43 pacientes, sendo $(62,8 \%)$ do sexo masculino e $(37,2 \%)$ do sexo feminino. Todos os pacientes foram submetidos à triagem prévia antes da polissonografia, sendo divididos em três grupos: Grupo I - com SAOS leve: 8 pacientes (18,6\%); Grupo II - com SAOS moderada: 18 pacientes (41,8\%); Grupo III - com SAOS grave: 17 pacientes (39,5\%). Conclusão: A síndrome da apneia do sono é comumente correlacionada à síndrome metabólica.

Descritores: Ronco. Apneia do sono. Polissonografia.

\section{INTRODUCTION}

Obstructive Sleep Apnea Syndrome (OSAS) is a disorder characterized by recurrent collapses of the pharynx during sleep, resulting in a substantial reduction in airflow (apnea and hypopnea), despite respiratory efforts ${ }^{1}$. Its importance resides in the impact on the quality of life of the affected individual and in the morbidity associated with this disease. OSAS is responsible for symptoms such as excessive daytime sleepiness, cognitive problems, and significant increase in the risk of work and traffic accidents, in addition to being considered an independent risk factor for cardiovascular diseases ${ }^{1}$.

The diagnosis for OSAS is based on clinical history, ENT physical examination, including nasofibrolaryngoscopy, blood pressure measurement, calculation of body mass index (BMI), measurements of cervical and abdominal circumference and polysomnography ${ }^{2}$. This is considered the gold standard in the diagnosis of OSAS, using the apnea-hypopnea index to classify the degree of severity of the disease ${ }^{3}$.

On physical examination, $\mathrm{BMI}$ above 30 and cervical circumference greater than $43 \mathrm{~cm}$ in men and $40 \mathrm{~cm}$ in women increase the chance of the patient presenting the disease ${ }^{1}$. In addition, patients with increased abdominal circumference $(\geq 102 \mathrm{~cm}$ in men and $\geq 88 \mathrm{~cm}$ in women) have a criterion for metabolic syndrome ${ }^{4}$.

Excessive daytime sleepiness (EDS) represents the main sequel of sleep fragmentation and can be assessed subjectively by scales, such as the Epworth Sleepiness Scale, which suggests apnea when above $10^{2,5}$. The scale is useful for diagnostic investigation and outpatient follow-up of patients after clinical and/or surgical treatments ${ }^{2}$. 
The greatest risk factors for OSAS are age, male gender and obesity, although the exact mechanisms are not yet fully understood ${ }^{1}$. These factors may explain the increase in anatomical impairment of the pharynx, the reduction in the function of the pharyngeal dilator muscles, the reduction of the threshold for cortical awakening, the increase in the instability of ventilatory control and the reduction of lung volume ${ }^{1}$.

Treatments usually consists into clinical and surgical, although some patients require combined treatments ${ }^{2}$. As options for clinical therapy, there is the performance of oropharyngeal exercises ${ }^{6}$, the use of intraoral devices and positive pressure air ejection devices. The pharyngeal surgeries most used in the treatment of OSAS are uvulopalatopharyngoplasty, uvulopalatoplasty with laser or radiofrequency and lateral pharyngoplasty ${ }^{2}$.

Friedman et al. identified the main predictive factors for the success of uvulopalatopharyngoplasty the modified Mallampati score, the size of the palatine tonsils and the $\mathrm{BMI}^{2}$. From this, they divided the patients into four stages, according to stage I, he reports success of $80 \%$, for II, $40 \%$, for III, $8.1 \%^{2}$. Stage IV patients are not candidates for surgical treatment on the soft palate ${ }^{2}$.

\section{METHODS}

The present study was approved under no. 2.989.730, according to Regulatory Standard on Humans Reseach of Ministry Health Resolution 466/2012.

The study is a retrospective, cross-sectional study, using data obtained by clinic of the Department of Otorhinolaryngology and Head and Neck Surgery at Hospital Universitário Onofre Lopes between the years 2017 and 2019.

Researchers collected the following data: sex, gender, age, associated symptoms, medications in use, comorbidities, and classification on the Epworth scale, apnea/hypopnea index, obtained from the records of the type III polysomnography device (Stardust Phillips ${ }^{\circledR}$ ). On physical examination, cervical and abdominal circumferences, weight, height and grade of the palatine tonsils were evaluated to apply the body mass index (BMI) and Mallapatti classifications.

Regarding the apnea/hypopnea index (AHI), patients were grouped in the following classification, according to the recommendations of the American Academy of Sleep Medicine: mild OSA (IAH 5 to 15 events/ hour), moderate OSA (IAH of 16 to 30 events/hour), severe OSAS (AHI> 30 events/hour).

The results were submitted to descriptive statistics using a software (SPSS v.16) for data analysis. 
Patients profile at the sleep apnea outpatient clinic at a University Hospital

Inacio NTD, et al

\section{RESULTS}

The medical records of 43 patients were evaluated, $62.8 \%$ male and $37.2 \%$ female. All patients underwent previous screening through anamnesis and physical examination at the general otorhinolaryngology outpatient clinic, being referred to the polysomnography exam and follow-up in the outpatient clinic for respiratory sleep disorders, from which they were divided into three groups: Group I - with mild OSAS: 8 patients (18.6\%), 6 (75\%) men and 2 (25\%) women; Group II - with moderate OSAS: 18 patients (41.8\%), $9(50 \%)$ men and 9 (50\%) women; Group III - with severe OSAS: 17 patients (39.5\%), 12 (70.6\%) men and $5(29.4 \%)$ women (figure 1 ).

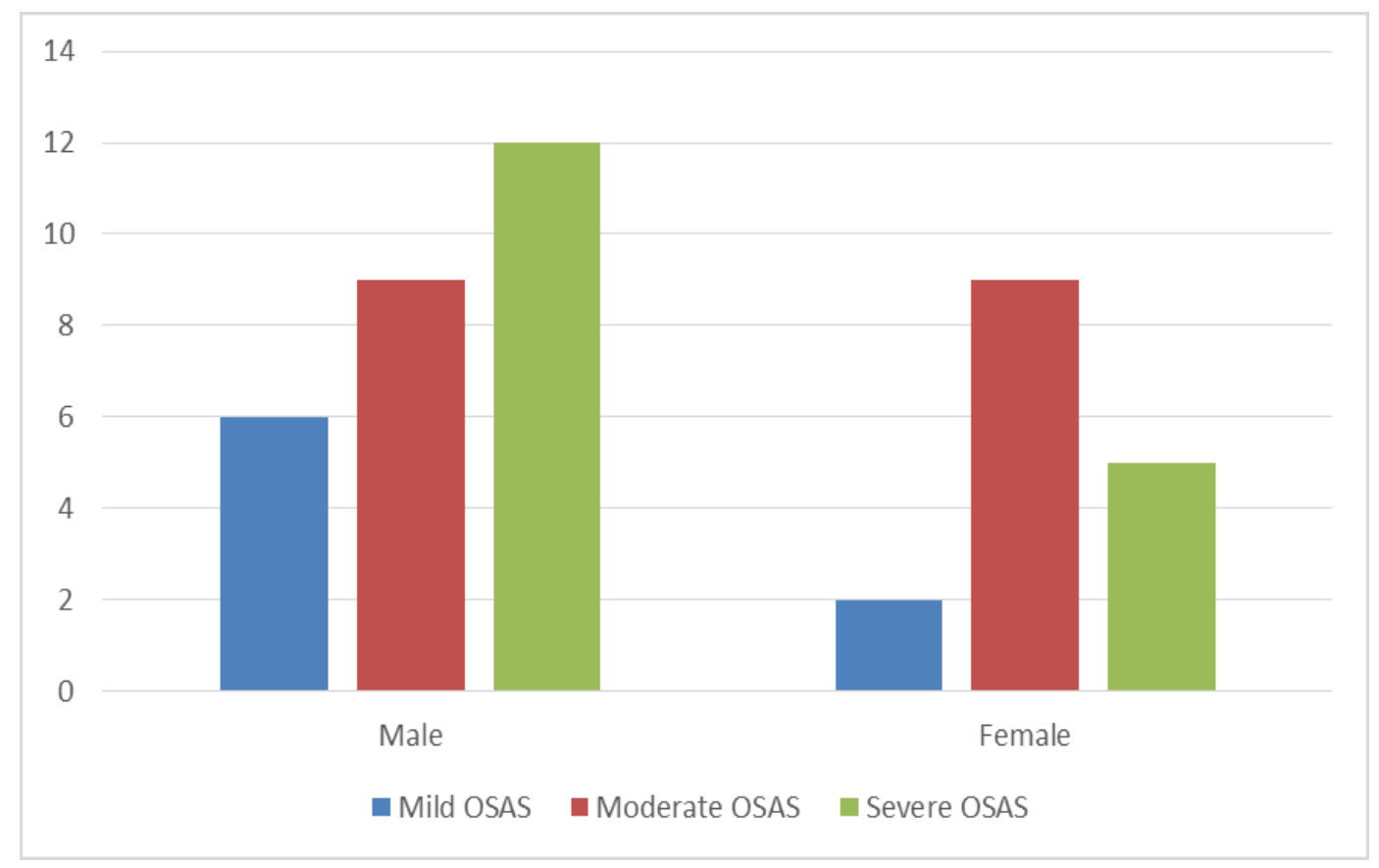

Figure 1. Distribution of OSAS according to severity and sex. Natal, RN

\section{Group I - mild OSAS.}

Patients with mild OSAS were mostly men (75\%), adults (100\%), with grade 1 obesity (50\%) and without associated comorbidities. In the anamnesis, they most often reported snoring (87.5\%), fatigued awakening (62.5\%) and awakening with respiratory distress (62.5\%). Through the Epworth scale, it was found that $62.5 \%$ of patients were at risk for apnea. On physical examination, $50 \%$ had an increase in waist circumference (figure 2).

\section{Group II - moderate OSAS}

In this group, there was no difference in relation to sex, with the same number of men and women. Most patients were adults (61.1\%) and with grade 1 obesity (55.6\%), with systemic arterial hypertension in $61.1 \%$ of cases. All patients, in addition to daytime sleepiness (72.2\%), fatigued awakening (66.7\%), nasal obstruction (55.6\%) and waking 
up with respiratory distress (44.4\%), reported snoring. The Epworth scale showed that $61.1 \%$ of patients were at risk for apnea. Only $26.7 \%$ had increased neck circumference, associated with $86.7 \%$ of patients with an increase in abdominal circumference (figure 2).

\section{Group III - severe OSA}

Group III was composed of $70.6 \%$ of adult men (88.2\%), being found overweight in $5.9 \%$, obesity grade 1 in $41.2 \%$, obesity grade 2 in $29.4 \%$ and obesity grade 3 in $23.5 \%$ of patients (graph 3 ), in addition to systemic arterial hypertension in $47.1 \%$ of cases. Once again, night snoring was the main symptom mentioned (100\%), associated with daytime sleepiness (70.6\%), fatigued awakening (52.9\%) and waking up with respiratory distress (70.6\%). The Epworth scale was able to screen $64.7 \%$ of cases. On physical examination, $35.7 \%$ and $84.6 \%$ had increased cervical and abdominal circumference, respectively (figure 2 ).

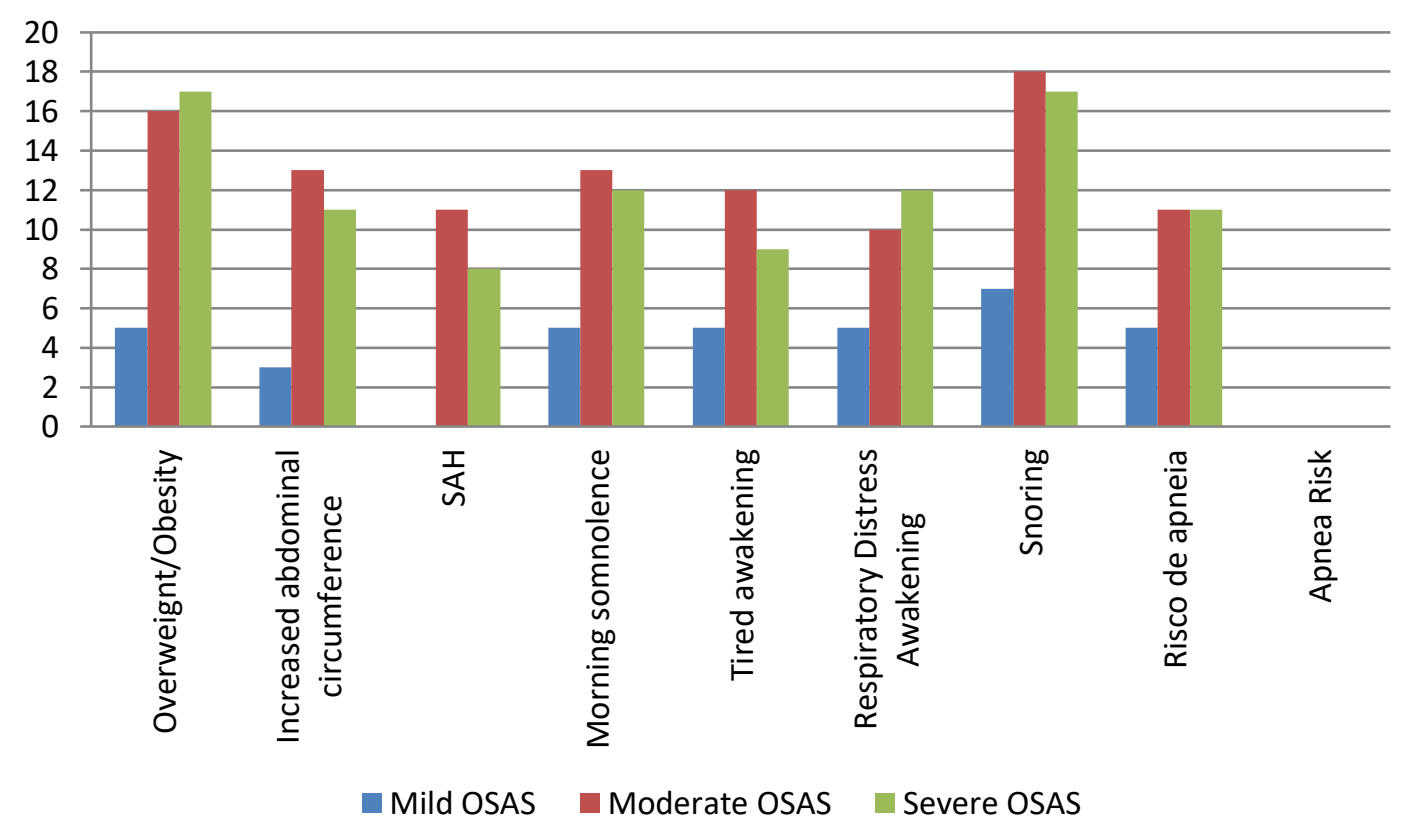

Figure 2 - Association of findings with the severity of OSAS 


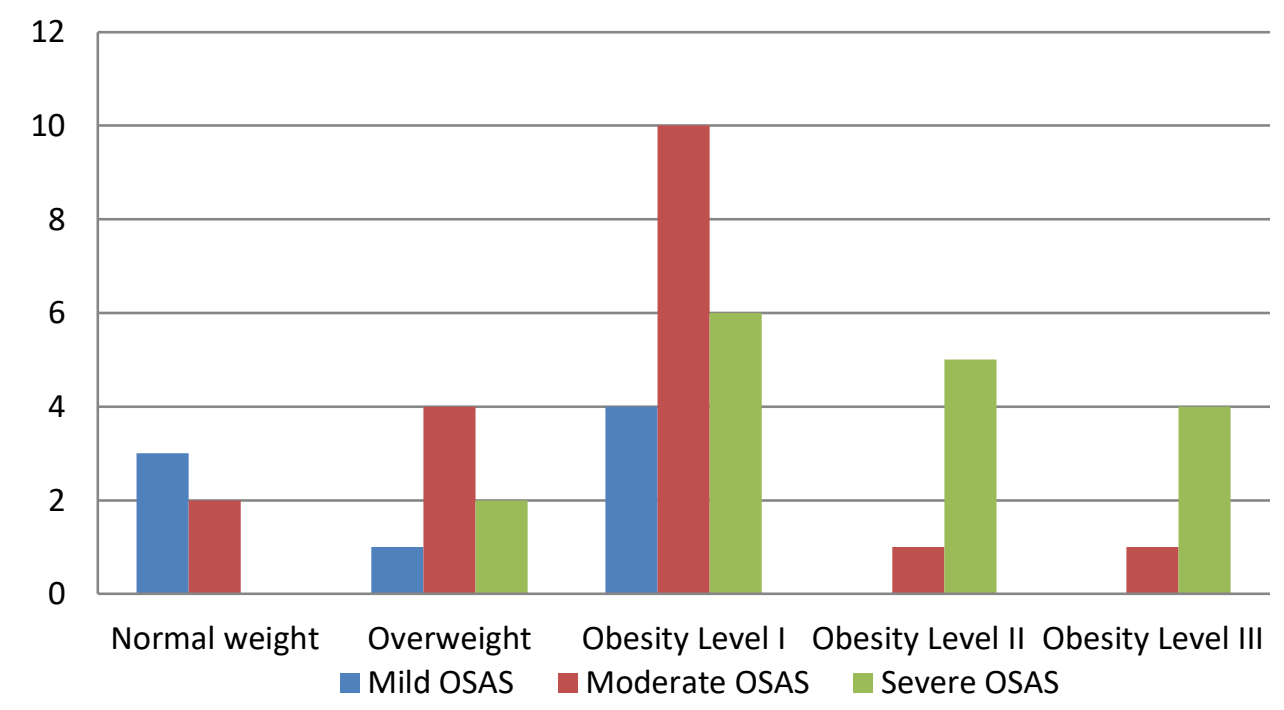

Figure 3 - OSAS X BMI

\section{DISCUSSION}

The studied patients presented the risk factors most cited in the literature, regardless of the severity of the disease, that is, the majority were adult men with overweight and obesity. In addition, it is clear that men are more affected by severe apnea than women who have more moderate apnea (Figure 1).

Through a detailed clinical history we were able to perform a good screening, since more than $60 \%$ of patients in each group were at risk of apnea by the Epworth Scale $(62.5 \%$ in mild OSAS, $61.1 \%$ in moderate OSAS and $64.7 \%$ in severe OSAS). This proves the importance of this scale in the screening of patients with sleep apnea.

When analyzing the most prevalent symptoms, it is clear that daytime sleepiness and fatigued awakening are highly valued, which leads us to realize that quality of life and daily performance are compromised in these patients. Thus, despite the fact that people value snoring complaints due to personal embarrassment or disturbance of their partners, excessive daytime sleepiness has a much greater impact on the personal lives of patients (Figure 2).

The study also demonstrates the close relationship between obstructive sleep apnea and metabolic syndrome. Although the pathological mechanisms involved are poorly understood, there is strong evidence for an association between OSAS, obesity, type 2 diabetes mellitus and non-alcoholic fatty liver disease ${ }^{4,7}$.

All groups in the study had some degree of overweight and obesity, with an increase in BMI with worsening of OSAS. In addition, more than $80 \%$ of patients with moderate or severe OSAS have changes in waist circumference (men>102 cm and women $>88 \mathrm{~cm})$, adding another criterion for metabolic syndrome. 
Systemic arterial hypertension is the risk factor for cardiovascular diseases most associated with OSAS. Studies have shown that 30-40\% of hypertensive patients have OSAS and that $50 \%$ of patients with OSAS have a history of hypertension ${ }^{8}$. These data are consistent with the findings of this research, since $61.1 \%$ of patients with moderate OSAS and $47.1 \%$ of patients with severe OSAS were also hypertensive. However, there is a lower incidence of SAH in patients with severe OSAS than in those with moderate OSAS, which can be justified by the greater number of patients with moderate degree or by a measurement error during data collection.

Therefore, there is no doubt that sleep apnea contributes to the increased risk of cardiovascular disease, drawing doctors' attention to the need for early diagnosis and treatment of these patients. The benefits of therapy for OSAS imply in improving the quality of life, performance at work and reducing the risk of diseases such as acute myocardial infarction and stroke.

\section{CONCLUSION}

The sleep apnea syndrome commonly coexists with the metabolic syndrome, as most patients are overweight or obese and systemic arterial hypertension. These people are more vulnerable to the morbidity associated with cardiovascular diseases, therefore, early diagnosis and treatment is necessary in order to avoid an increase in mortality.

\section{REFERENCES}

1. Pignatari SSN, Anselmo-Lima WT, organizadores. Tratado de Otorrinolaringologia. 3. ed. São Paulo. Elsevier Editora Ltda.; 2018

2. Piltcher OB, Costa SS, Maahs GS, Kuhl G, organizadores. Rotinas em otorrinolaringologia. 1. ed. Porto Alegre. Artmed Editora Ltda. 2015

3. Kapur VK, Auckley DH, Chowdhuri S, Kuhlmann DC, Mehra R, Ramar et al. Clinical practice guideline for diagnostic testing for adult obstructive sleep apnea: an American academy of sleep medicine clinical practice guideline. J Clin Sleep Med. 2017;13(3):479-503.

4. Carneiro G, Fontes FH, Guimarães SM, Togeiro SMGP. Consequências metabólicas na SAOS não tratada. J Bras Pneumol. 2010;36(supl.2):S1-S61.

5. Araújo-Melo MH, Neves DD, Ferreira LVMV, Moreira MLV, Nigri R, Simões SMG. Questionários e escalas úteis na pesquisa da Síndrome da Apneia Obstrutiva do Sono. Revista HUPE, Rio de Janeiro, 2016;5: 48-54.

6. Guimarães KCC. Efeitos dos exercícios orofaríngeos em pacientes com apneia do sono moderada: estudo controlado e randomizado. São Paulo. Tese (Doutorado em ciências): Faculdade de Medicina, Universidade de São Paulo; 2008.

7. Min L, Xiaoying L, Yan L. Obstructive Sleep Apnea Syndrome and Metabolic Diseases. Endocrinology, July 2018; 159(7):2670-2675. 
Patients profile at the sleep apnea outpatient clinic at a University Hospital

Inacio NTD, et al

8. Gonzaga C, Bertolami A, Bertolami M, Amodeo C, Calhoun D. Obstructive sleep apnea, hypertension and cardiovascular diseases. Journal of Human Hypertension, 2015 march. 